\title{
Piercing the Smoke Screen: Dualism, Free Will, and Christianity
}

\author{
(forthcoming in Journal of Cognition \& Culture)
}

Samuel Murray, Duke University

Elise Dykhuis, Wake Forest University

Thomas Nadelhoffer, College of Charleston

\section{Abstract}

Research on the folk psychology of free will suggests that people believe free will is incompatible with determinism and that human decision-making cannot be exhaustively characterized by physical processes. Some suggest that certain elements of Western cultural history, especially Christianity, have helped to entrench these beliefs in the folk conceptual economy. Thus, on the basis of this explanation, one should expect to find three things: (1) a significant correlation between belief in dualism and belief in free will, (2) that people with predominantly incompatibilist commitments are likely to exhibit stronger dualist beliefs than people with predominantly compatibilist commitments, and (3) people who self-identify as Christians are more likely to be dualists and incompatibilists than people who do not self-identify as Christians. We present the results of two studies $(n=378)$ that challenge two of these expectations. While we do find a significant correlation between belief in dualism and belief in free will, we found no significant difference in dualist tendencies between compatibilists and incompatibilists. Moreover, we found that self-identifying as Christian did not significantly predict preference for a particular metaphysical conception of free will. This calls into question assumptions about the relationship between beliefs about free will, dualism, and Christianity.

\section{Introduction}

Kant famously argued that human beings could be free only if there is some realm of objects that exists outside the natural world that serves as the ground of freedom (Kant, 1998: A545/B563). Kant represents an extreme view within a tradition of theorists who see a tension between free will and naturalism, or the thesis that everything either is or is constituted by physical entities. Spinoza occupies the other extreme. He accepts that the laws of nature causally necessitate the activity of every natural entity. People, being parts of nature, are determined to behave as they do by the laws of nature, thereby excluding freedom (Ethics Ip32). 
One rough reconstruction of the line of thinking underlying this tradition is the following. Freedom is incompatible with either determinism or randomness. Our best scientific theories claim that the natural world is either fundamentally deterministic or random and, hence, that the activity of entities in this world are either completely determined or wholly random. So, believing that anything acts freely is inconsistent with a mature scientific view of the world. Kant's response to this argument is to say that naturalism is false and there is something beyond the natural world that preserves freedom, while Spinoza responds by rejecting freedom and upholding naturalism.

This line of thinking does not accurately capture the wide range of views of contemporary theorists working on the problem of free will. Many accept the claim that freedom is compatible with determinism, and one alleged theoretical virtue of compatibilism is its congruence with a naturalist view of the world (Mele, 2014; Nahmias, 2014; Vargas, 2014). Moreover, there are others who accept the incompatibility of free will and determinism, but reject the claim that naturalism rules out freedom. Some have proposed metaphysical frameworks consistent with naturalism that can account for an incompatibilist view of free will (see Jacobs \& O'Connor, 2013; Timpe \& Jacobs, 2016; Steward, 2012; Lowe, 2013).

While the traditional line of thinking about free will might depart significantly from the professional opinions of contemporary academics, the argument still seems to accurately 
characterize commonsense thinking about free will. Consider the following perspectives on everyday opinions of free will:

"Free will is the idea that we make choices and have thoughts independent of anything remotely resembling a physical process" (Montague, 2008: 584).

"Most people's view of the mind is implicitly dualist and libertarian" (Greene \& Cohen, 2004: 1779).

Some experimental work on intuitions about free will supports this characterization of folk thinking. In one of the earliest studies of people's beliefs about free will, Nichols \& Knobe (2007) found that a majority of people gave responses that aligned with incompatibilism when presented with abstract moral scenarios and questions. Other empirical work shows that people think human decision-making is the only process that is exempt from the constraints of physical laws (Knobe, 2014). Recent work reveals connections between belief in free will and belief in dualism (see Nadelhoffer et al., 2014; Forstmann \& Burgmer, 2018). ${ }^{2}$

While this seems to support the characterization of folk thinking as inherently incompatibilist and dualist, other experimental work has provided some modest pushback. Nahmias and colleagues have found that when people are prompted to make

\footnotetext{
${ }^{1}$ A libertarian about free will is committed to the truth of two claims: (1) It is not possible for anything to have free will in a universe where the thesis of determinism is true, and; (2) At least one thing in this universe has free will for at least one moment in time.

${ }^{2}$ We provide more precise characterizations of physicalism and naturalism in the General Discussion.
} 
judgments of free will in response to concrete cases, people have robustly compatibilist intuitions (Nahmias et al., 2005, 2006; see also Murray \& Nahmias, 2014). Moreover, both Monroe \& Malle (2010) and Nahmias (2011) found no evidence that belief in free will requires belief in substance dualism.

Two responses have been made to address these apparently conflicting findings. The first is clarification. Research has shown relationships between free will belief and the rejection of reductive physicalism (De Brigard, Mandelbaum, \& Ripley, 2009; Deery, Davis, \& Carey, 2014; Nadelhoffer et al., 2014). Thus, belief in free will presupposes that, for example, the mind does not reduce to the brain or that human behavior cannot be exhaustively characterized in terms borrowed from the sciences. These claims hardly constitute an acceptance of substance dualism. The second is to concede that people might not exhibit unified thinking about free will. Our ordinary folk conceptions of various phenomena are likely patchwork collections of different criteria that differentially inform judgments across contexts. The claim that folk thinking is incompatibilist merely requires that incompatibilist commitments constitute at least part of our ordinary conception, even if compatibilist commitments can be activated in certain contexts (see Vargas, 2013: 37-40; cf. Knobe and Doris, 2010). Further, it should be noted that the connection between free will belief and dualism has recently been replicated in a largescale multi-cultural study, thereby offering support to the idea that there are important connections between dualism and free will in the folk concept (see Wisniewski, Deutschländer, and Haynes, 2019). 
This experimental work has converged on three findings: (1) many people believe that human beings have free will; (2) this belief in free will correlates highly with belief in dualism, and; (3) many people have a (perhaps context-sensitive) belief in incompatibilism.

Some have suggested that elements of Western cultural history have helped entrench these elements in the folk conceptual economy. Christianity packages dualism, incompatibilism, and belief in free will into a complete metaphysical/theological view. Some strands in Christian theology posit incompatibilism as a way of reconciling the coexistence of an all-good, all-powerful, all-knowing God with the existence of moral evil while absolving God of moral responsibility for such evils. Further, the Christian intellectual tradition typically trades in ontologies that include irreducible non-physical entities (souls, minds, etc.). Jesus himself seems to endorse a distinction between the physical and the spiritual realms, saying: “...the spirit indeed is willing, but the flesh is weak" (Matt. 26:41, ESV translation). The Catechism of the Catholic Church reifies this statement into a metaphysical principle:

The unity of soul and body is so profound that one has to consider the soul to be the 'form' of the body: i.e., it is because of its spiritual soul that the body made of matter becomes a living, human body; spirit and matter, in man, are not two nature united, but rather their union forms a single nature $(\S 365)$. 
This does not show that belief in dualism and incompatibilism are constitutive of membership in the Christian faith; rather, the argument is that the framework of Christianity brings with it demanding ontological commitments. Because Christians are antecedently committed to a metaphysically thick framework, the conceptual cost of committing to libertarian forms of agency are lowered (see Vargas, 2013: 40-43). As Manuel Vargas puts it: “...a libertarian conception of agency might seem a reasonable corollary to a dualistic metaphysics" (Vargas, 2013: 41).

If this diagnosis is correct, we should expect to see the following three things:

1) A significant correlation between belief in dualism and belief in free will.

2) People with predominantly incompatibilist commitments are likely to exhibit stronger dualist beliefs than people with predominantly compatibilist commitments.

3) People who self-identify as Christians are more likely to be dualists and incompatibilists than people who do not self-identify as Christians.

While there is some evidence to support each of these claims, there is also reason for doubt. For one, there is a rich tradition within Christian intellectual history of compatibilists, including Augustine, Aquinas, Hobbes, Calvin, Luther, Locke, Leibniz, and Jonathan Edwards (among others). The Christian tradition is certainly not homogenous with respect to theories of free will. ${ }^{3}$

\footnotetext{
${ }^{3}$ In fact, Pope Clement VIII issued a decree in 1611 (and again in 1625) prohibiting further discussion on the relationship between efficacious grace and free will. This prohibition reinforced the 1597 decision to abstain from adjudicating the dispute between the Dominicans and the Jesuits on grace and free will. In short, the Catholic Church decided to remain officially undecided on matters pertaining to free will. The
} 
Likewise, Christianity has a complicated relationship with dualistic metaphysics. Consider another passage from the Catechism:

Sometimes the soul is distinguished from the spirit: St. Paul for instance prays that God may sanctify his people 'wholly', with 'spirit and soul and body' kept sound and blameless at the Lord's coming. The Church teaches that this distinction does not introduce a duality into the soul (§367; emphasis added).

Hobbes and Leibniz also reject dualism, though in opposite directions. Hobbes thought that the metaphysical ground floor consisted in material substances (bodies) and that phrases like 'incorporeal substance' were nonsensical (see Leviathan 4.20-1). Leibniz, on the other hand, held that fundamental reality consisted in minds and that non-mental entities are merely aspects of qualitative features of minds (Leibniz, 1965: 270). Members of the Christian intellectual tradition do not unanimously endorse a single metaphysical framework for characterizing free will.

We designed a series of studies to test these predictions about the folk conceptual framework of free will. Using the recently developed Free Will Inventory (Nadelhoffer et al., 2014), we measured belief in free will and dualism. We also included a forced choice item associated with either an incompatibilist or compatibilist conception of free will. We

Church teaches only that human beings have free will, not to any substantive theory thereof: "Man is rational and therefore like God; he is created with free will and is master over his acts" (§1730). 
find that the relationship between free will, dualism, and Christianity is more complicated than has been previously admitted. This sheds further light on the structure of the folk conceptual framework concerning free will.

\section{Study 1}

\subsection{Participants}

Complete data sets and analyses can be found at: https://osf.io/cfdv3/. As we discuss below, the experiments we conducted were part of a larger, multi-factorial design developed for other purposes (the data and pre-registrations for this larger study can be found at https://osf.io/y3jeb/). Data and analyses for the studies reported here were conducted in accordance with pre-registered analyses for these other experiments. We indicate any post-hoc analyses that go beyond the original pre-registration and did not collect additional participants beyond what was planned in the pre-registration.

We recruited 200 participants to take part in a study on free will intuitions on Amazon's Mechanical Turk. ${ }^{4} 1$ participant failed to complete the study and we excluded 9 participants who failed an attention check (final $n=190$ ). ${ }^{5}$ Participants had to satisfy three conditions to qualify for the study: (a) they needed to have successfully completed

\footnotetext{
${ }^{4}$ MTurk is an online survey service that enables researchers to recruit and pay for participants for completing surveys of studies. For findings concerning the benefits of using MTurk - including the quality of the data and the improved diversity of the participant pool - see Burhmester, Kwang, \& Gosling (2011); Paolacci, Chandler, \& Ipeirotis (2010); Rand (2012). We also note that, while MTurk samples are representative of populations in WEIRD countries across many dimensions, they are typically much more likely to be atheist or agnostic relative to the general population (see Lewis et al., 2015).

${ }^{5}$ The two attention checks we used read:

1. Monday is the first day of the week. What is the third day of the week?

2. January is the first month of the year. What is the fifth month of the year? Participants could select their answers from a list of five options. The checks were included to ensure that participants were paying attention to the survey and not simply clicking through to get a compensation code.
} 
at least 500 HITS in the past, (b) they needed a HIT success completion rate of at least $97 \%$, and (c) they needed to be located in the United States. On average, participants took about 13 minutes to complete the study. They were paid $\$ 1.00$ for participating. The demographics for the 190 participants were as follows: $M_{\text {age }}=37.6$ years, $\mathrm{SD}=10.9$, range $_{\text {age }}=[19-70], 37.9 \%$ females, $70 \%$ Caucasian. The Institutional Review Board of the College of Charleston approved this study.

\subsection{Methods \& Materials}

Study 1 used a within-subjects design with seven stages. The principal aim of the study was to examine participants' comprehension of deterministic features of stimuli typically used in experimental studies of free will intuitions. Many of the stages used for that aim are not relevant to the present research question, so we do not describe them. There are four relevant stages. First, participants were asked to select between two statements that describe a way of thinking about free will:

1. To have free will is to be able to make different choices but only if something leading up to your choice (e.g., the past, the situation, and your desires, beliefs, etc.) had been different.

2. To have free will is to be able to make different choices even if everything leading up to your choice (e.g., the past, the situation, and your desires, beliefs, etc.) had been exactly the same. 
The first option aligns with a conception of free will amenable to compatibilism (see Lewis, 1981), while the second option aligns with a conception of free will amenable to incompatibilism (see van Inwagen, 2004). After making a selection, participants were presented with three subscales of the Free Will Inventory (FWI: see Nadelhoffer et al., 2014): the free will subscale, the determinism subscale, and the dualism subscale.

Because the determinism subscale is not relevant, we omit further discussion of it. Participants rated agreement with each item using a 7-point Likert scale $(1=$ strongly disagree; $4=$ neither agree nor disagree; $7=$ strongly agree). The items are listed below.

Free Will subscale

- People always have the ability to do otherwise.

- People always have free will.

- How people's lives unfold is completely up to them.

- People ultimately have complete control over their decisions and their actions.

- People have free will even when their choices are completely limited by external circumstances.

\section{Dualism subscale}

- The fact that we have souls that are distinct from our material bodies is what makes humans unique.

- Human action can only be understood in terms of our souls and minds and not just in terms of our brains.

- Each person has a non-physical essence that makes that person unique. 
- The human mind cannot simply be reduced to the brain.

- The human mind is more than just a complicated biological machine.

Note that the Free Will subscale measures belief in the existence of free will, though the questions are neutral between incompatibilist-friendly or compatibilist-friendly conceptions of free will. Hence, the Free Will subscale is not as theoretically loaded as the forced-choice item.

Participants then performed a distractor task, read a vignette, and answered some questions about the vignette. These were not relevant to the current research, so we do not describe them here. After this, we re-administered the FWI scales to ensure that reading the vignettes was not dramatically altering FWI responses. Finally, participants were presented with the forced-choice items. We wanted to make it more difficult for people to complete the second round of FWI items by simply selecting the answers they used before, so we interspersed ten items from the Humility Scale (Wright et al., 2017) with the items from FWI for both the pre- and post-administration of FWI. All items were randomly presented. We collected demographic information from participants at the end of the study, including religious affiliation. Participants had the option to self-identify with a religious group from a drop-down menu that included: Christianity, Hindu, Islam, Buddhism, Judaism, Atheism, Agnosticism, Other, None.

\subsection{Results}

To categorize FWI scale responses, we computed the average of responses on each subscale. Mean scores above (but not including) 4 were counted as agreement, while 
anything below (but not including) 4 was counted as disagreement. Hence, an average score above 4 on the free will subscale indicates belief in free will, an average score above 4 on the determinism subscale indicates belief in determinism, and an average score above 4 on the dualism subscale indicates belief in dualism.

$$
80 \% \text { of participants }(n=152) \text { registered belief in free will and } 76.3 \% \text { of }
$$

participants $(n=145)$ registered belief in dualism. $79.5 \%$ of participants $(n=151)$ agreed with the incompatibilist conception of free will on the forced choice item, whereas $20.5 \%$ $(n=39)$ agreed with the compatibilist conception of free will. These numbers exceed the number of participants who believe in free will, though this might be due to the fact that some people think free will has a certain structure, but the conditions for having free will are not satisfied in our universe. ${ }^{6}$

We collected data about participant's free will and dualism beliefs at the beginning and the end of the study. An independent samples t-test revealed significant differences between these scores for both dualism $(t(189)=-2.45, p<.05)$ and free will $(t(189)=-2.08, p<.05)$ ratings. However, mean ratings for each category were very similar (beginning dualism $M=4.85(S D=1.61)$, end dualism $M=4.94(S D=1.64)$, beginning free will $M=5.06(S D=1.33)$, end free will $M=5.16(S D=1.36))$. We ran simple linear regressions to test the relation between pre- and post-assessment scores. Dualism scores were highly correlated $(r=.948, p<.001)$ and free will scores were highly correlated $(r=.888, p<.001)$. Moreover, the correlations we report below do not change significantly in virtue of using pre- or post-assessment scores. So, even though we

\footnotetext{
${ }^{6}$ That is, some participants might think that free will is incompatible with determinism, thereby selecting the incompatibilist forced-choice item. But, these same participants think that the universe is deterministic, so they do not believe that anyone in this universe has free will.
} 
found a statistically significant difference in ratings offered at the beginning of the assessment and at the end, the strong correlations indicate that these answers are similar. Thus, for simplicity, we report statistical tests for a single time point (pre-assessment scores). All correlations are listed in Table 1.

Table 1. Correlations for all Dependent Variable between all Time Points

\begin{tabular}{|l|c|c|c|c|}
\hline & Pre-Dualism & Post-Dualism & Pre-Free Will & Post Free Will \\
\hline Pre-Dualism & & $.948^{* *}$ & $.395^{* *}$ & $.352^{* *}$ \\
\hline Post-Dualism & $.948^{* *}$ & & $.379^{* *}$ & $.381^{* *}$ \\
\hline Pre-Free Will & $.395^{* *}$ & $.379^{* *}$ & & $.888^{* *}$ \\
\hline Post-Free Will & $.352^{* *}$ & $.381^{* *}$ & $.888^{* *}$ & \\
\hline
\end{tabular}

$* *=p<.001$

Belief in dualism and belief in free will were significantly correlated $(r=.395, p$ $<.001)$. However, participants who selected the compatibilist forced-choice item scored higher on the dualism subscale on average than participants who selected the incompatibilist forced-choice item (Compatibilist: $M=5.13, S D=1.28$; Incompatibilist: $M=4.78, S D=1.68)$. An independent samples t-test did not identify a statistically significant difference between these average ratings $(t(75.89)=-1.45, p>.05)$.

At the end of the study, 187 participants self-identified as affiliating with a particular religious group (see Table 2) 
Table 2. Breakdown of Religious Affiliation in Study 1 with Dualism and Free Will Ratings

\begin{tabular}{|c|c|c|c|}
\hline Religion & Number & Free Will (SD) & Dualism (SD) \\
\hline Christian & 95 & $5.37(1.07)$ & $5.56(1.1)$ \\
\hline Agnostic & 23 & $5.49(1.07)$ & $3.94(1.77)$ \\
\hline Atheist & 34 & $4.62(1.5)$ & $3.60(1.61)$ \\
\hline Other & 12 & $5.43(.55)$ & $5.33(.63)$ \\
\hline None & 23 & $5.49(1.07)$ & $3.94(1.77)$ \\
\hline
\end{tabular}

An independent samples t-test identified a significant relationship between dualism and religious affiliation $(F(4,182)=17.80, p<.001)$. Post-hoc Bonferroni comparisons showed that those who identified as Christian rated dualism statistically significantly higher than all other religious groups (all $p<.001)$.

We conducted a chi-square test of independence to examine the relationship between religion and belief in incompatibilism. Results indicated that those who identified as Christians were statistically significantly more likely to be incompatibilists than members of other religious groups $\left(\chi^{2}(4, N=187)=12.56, p=.014\right)$. See Table 3 for expected and observed counts.

Table 3. Expected Counts of Compatibilists and Incompatibilists by Religious Affiliation in Study 1

\begin{tabular}{|l|l|l|l|l|l|l|l|}
\hline & & Christianity & Other & Atheist & Agnostic & None & Total \\
\hline Compatibilist & Count & 37 & 7 & 7 & 4 & 4 & 59 \\
\hline
\end{tabular}




\begin{tabular}{|l|l|l|l|l|l|l|l|}
\hline & Expected & 30 & 3.8 & 10.7 & 7.3 & 7.3 & 59 \\
\hline Incompatibilist & Count & 58 & 5 & 27 & 19 & 19 & 128 \\
\hline & Expected & 65 & 8.2 & 23.3 & 15.7 & 15.7 & 128 \\
\hline Total & Count & 95 & 12 & 34 & 23 & 23 & 187 \\
\hline & Expected & 95 & 23 & 34 & 23 & 23 & 187 \\
\hline
\end{tabular}

\subsection{Discussion}

We found, in support of the popular characterization of free will and dualism beliefs, that there is a moderate correlation between belief in dualism and belief in free will. However, contrary to the popular characterization, we found that compatibilists exhibit equally strong belief in dualism as incompatibilists. Religion also played an important role. Christians were more likely to exhibit both dualist beliefs and select the incompatibilist forced-choice item relative to members of other religious groups. However, as the expected counts show, there are more Christians that identify as compatibilist than is expected and fewer Christians who identify as incompatibilist than is expected. This pattern is reversed in other religious groups. So even though Christians are more likely to exhibit stronger dualist tendencies relative to members of other religious groups, there is not a clear propensity to identify as incompatibilist relative to other religious groups.

Hence, we find partial support for part of the popular characterization. Christians are more likely than others to exhibit dualist beliefs. However, contrary to the popular characterization, we found that compatibilists and incompatibilists have similar levels of belief in dualism. 
We conducted another study to see if these results replicate.

\section{Study 2}

\subsection{Participants}

We recruited 200 participants through Amazon's Mechanical Turk. 198 participants completed the study. Conditions to qualify for the study were the same as Study 1. On average, participants took about 15 minutes to complete the study, and they were paid $\$ 1$ for participating. We excluded 10 participants who failed either of two attention checks (final $n=188 ; M_{\text {age }}=35.7$ years, $S D=10.7$ range $_{\text {age }}=[19-70], 32 \%$ females, $66 \%$ Caucasian). The Institutional Review Board of the College of Charleston approved this study.

\subsection{Methods \& Materials}

We used the same methods and materials as in Study 1 with one exception. We used a different vignette in this study. However, like the previous study, this vignette (and the subsequent responses) is not relevant to the current research, so we do not describe these materials further.

\subsection{Results}

Similar to Study 1, we again found high rates of belief in free will $(80.3 \%, n=151)$, belief in dualism $(75 \%, n=141)$, and belief in incompatibilism $(69 \%, n=129)$. We also found a modest correlation between belief in dualism and belief in free will $(r=.285, p<$ .001). An independent samples t-test revealed no statistically significant difference 
between pre- and post-assessment ratings of dualism or free will. For this reason, we do not report all correlations between dependent variables at all time points. Instead, for simplicity, we simply report correlations using pre-assessment ratings.

Similar to Study 1, participants who selected the compatibilist item scored higher on the dualism subscale relative to incompatibilists (Compatibilist: $M=5.24, S D=1.18$; Incompatibilist: $M=4.67, S D=1.68)$. An independent samples t-test revealed a statistically significant difference between these groups $(t(186)=2.381, p=.017)$.

We again found a significant relationship between religious affiliation and belief in dualism. Two participants did not disclose their religious affiliation, resulting in 186 participants for these analyses. Table $\mathbf{4}$ describes the number of participants in each religious group, as well as their respective mean scores on the free will and dualism subscales.

Table 4. Breakdown of Religious Affiliation in Study 2 with Dualism and Free Will Ratings

\begin{tabular}{|c|c|c|c|}
\hline Religion & Number & Free Will (SD) & Dualism (SD) \\
\hline Christian & 85 & $5.38(1.11)$ & $5.61(1.02)$ \\
\hline Agnostic & 30 & $4.75(1.27)$ & $4.39(1.52)$ \\
\hline Atheist & 26 & $4.68(1.83)$ & $3.58(1.77)$ \\
\hline Other & 7 & $4.60(0.59)$ & $4.37(1.6)$ \\
\hline None & 38 & $5.03(1.42)$ & $4.46(1.90)$ \\
\hline
\end{tabular}


An independent sample t-test indicated a statistically significant relationship between dualism and religious affiliation $(F(4,181)=12.49, p<.001)$. Post-hoc Bonferroni comparisons showed that those who identified as Christians rated dualism statistically significantly higher all other religious groups (all $p<.001$ ) except for Other. However, this lack of significant difference may stem from the fact that this category included too few participants for us to make reliable and valid comparisons.

We conducted a chi-square test of independence to measure the relationship between religion and belief in incompatibilism. Unlike Study 1, we did not find a significant difference between groups $\left(\chi^{2}(4, \mathrm{~N}=186)=7.080, p=.132\right)$. Thus, selecting the incompatibilist item over the compatibilist item did not differ significantly by religious affiliation. We found a similar pattern in expected counts as in Study 1 (see

Table 5).

Table 5. Expected Counts of Compatibilists and Incompatibilists by Religious Affiliation in Study 2

\begin{tabular}{|l|l|l|l|l|l|l|l|}
\hline & & Christianity & Other & Atheist & Agnostic & None & Total \\
\hline Compatibilist & Count & 22 & 3 & 2 & 5 & 6 & 38 \\
\hline & Expected & 17.4 & 1.4 & 5.3 & 6.1 & 7.8 & 38 \\
\hline Incompatibilist & Count & 63 & 4 & 24 & 25 & 32 & 148 \\
\hline & Expected & 67.6 & 5.6 & 20.7 & 23.9 & 30.2 & 148 \\
\hline Total & Count & 85 & 7 & 26 & 30 & 38 & 186 \\
\hline & Expected & 85 & 7 & 26 & 30 & 38 & 186 \\
\hline
\end{tabular}

\subsection{Discussion}


We replicated the correlation between belief in free will and belief in dualism. In this study, we also found that selection of the compatibilist item corresponds with significantly higher ratings on the dualism subscale relative to those that select the incompatibilist item. This cuts against the popular characterization that belief in dualism goes hand in hand with incompatibilist conceptions of free will, though we do find that belief in free will is associated with belief in dualism.

We also did not replicate the finding that Christians are much more likely than others to select the incompatibilist item. This provides further support for the claim that Christianity does not predict allegiance to one or another metaphysical conception of free will.

\section{General Discussion}

John Calvin once wrote that "Knowledge of the sciences is so much smoke apart from the heavenly science" (Commentary on 1 Corinthians 1:19-20). We are not here to engage in heavenly science or weigh in on the finer points of Calvinist theology. We do, however, think that there is a smoke screen surrounding contemporary characterizations of the psychological relationship between belief in free will, dualism, and Christianity. We hope that our results are a first attempt to pierce through this smoke screen to reveal a more complicated underlying reality.

Recall that we wanted to test three claims:

1) There is a significant correlation between belief in dualism and belief in free will. 
2) People with predominantly incompatibilist commitments are likely to exhibit stronger dualist beliefs than people with predominantly compatibilist commitments.

3) People who self-identify as Christians are more likely to be dualists and incompatibilists than people who do not self-identify as Christians.

Across two studies, we found good support for the first claim. There is a modest correlation between belief in dualism and belief in free will. We did not find evidence supporting the second claim. In one study, we found no difference between the dualism ratings of compatibilists and incompatibilists. In another study, we found that people who made responses consistent with a compatibilist conception of free will scored significantly higher on the dualism subscale relative to those whose responses are consistent with an incompatibilist conception of free will. Thus, compatibilists exhibit stronger dualist tendencies relative to incompatibilists. Finally, our results were mixed with respect to the final claim. In one study, we found that Christians were significantly more likely to make responses consistent with incompatibilism relative to members who self-identify as part of a different religious group. However, we did not replicate this finding in a follow-up study. We also observed more Christians aligning with compatibilism than expected and fewer Christians aligning with incompatibilism than expected (we found the reverse trend in other religious groups).

Before drawing any conclusions, we want to point out two important limitations of our studies related to our sample. Population samples from MTurk draw extensively from WEIRD (Western, European, Industrialized, Rich, Developed) countries, with around $75 \%$ of workers located in the United States. Experiments conducted in non- 
WEIRD populations (or on non-WEIRD samples) tend to vary from those conducted in WEIRD populations (see Henrich, Heine, \& Norenzayan, 2010). Given that our experiments deal with institutions and practices that are subject to substantial degrees of cultural influence, we need to be cautious about over-generalizing our results. Moreover, MTurk workers tend to be much less religious (i.e., either agnostic or atheist) relative to the general population (see Lewis, Djupe, Mockabee, \& Su-Ya Wu, 2015). This means that the religious ideology of the average MTurk worker (and the related web of interconnected beliefs that include religiously motivated views about free will) might diverge from the general population. Further work should be done to replicate these results with non-online samples to validate the current findings.

We think that these results indicate something interesting about people's underlying beliefs about free will. At its core, the debate between incompatibilism and compatibilism that forms part of the problem of free will is a conceptual debate about the logical relationship between free will and the truth of determinism. People who work on the problem of free will see an important connection to naturalism because incompatibilist forms of agency are seen as more demanding than compatibilist forms of agency relative to standards of naturalistic plausibility (see Vargas, 2013: 66-67). Thus, someone committed to naturalism might adopt a compatibilist view of free will as a way of accommodating naturalist tendencies. This supports the illusion that incompatibilist views of free will align with dualism and compatibilist views of free will align with a rejection of dualism.

Our results show that this is not an accurate characterization of people's underlying beliefs. Instead, there is a relationship between belief in free will and belief in 
physicalism (or, more properly, reductive forms of physicalism). Roughly, naturalism is an ontological thesis about what kinds of things exist. On most versions of naturalism, the only things that exist are part of the natural world and could, at least in principle, be the object of scientific inquiry. ${ }^{7}$ Physicalism is the thesis that everything that exists is fundamentally composed of physical elements (put another way, physicalism is the thesis that there is nothing over and above physical objects, laws, events, and properties). One version of physicalism (reductive physicalism) holds that the behavior of everything can be exhaustively characterized in terms that are acceptable to a theory of physics. Another version of physicalism (non-reductive, or emergent, physicalism) holds that there are parts of reality over and above the physical. For example, there might be laws of biology, psychology, or economics that are essential to describing reality but nevertheless cannot be reduced to laws of physics. Note that, when distinguished in this way, physicalism entails naturalism, though naturalism does not entail a specific version of physicalism (the entailments are a little trickier than we let on here; see Kim, 2011).

Our results indicate that belief in free will correlates with a rejection of reductive physicalism. That is, if free will exists, then it must be composed of something above and beyond the scope of physics. People tend to exhibit anti-reductionist biases, seeing mechanistic characterizations of behavior and thought as inconsistent with free will and responsibility (see De Brigard, Mandelbaum, \& Ripley, 2009). This suggests that people view free will as an emergent property, and might explain why people believe that free will is grounded in having a non-physical mind or immaterial soul. However, our

\footnotetext{
${ }^{7}$ This is a description of ontological naturalism. A related thesis is methodological naturalism, which concerns the proper principles that guide scientific inquiry. The two theses are distinct, however, and we will concern ourselves only with the ontological form of naturalism.
} 
measures do not allow us to sort out whether free will beliefs are driven by a positive belief in metaphysical dualism or a rejection of reductive physicalism.

Our results about the relationship between Christianity, dualism, and incompatibilism are not straightforward. In one study, we found that self-identifying as a Christian predicts incompatibilism more than any other religious affiliation. However, we did not replicate this result in Study 2. Hence, we think more work should be done to uncover the conceptual and psychological relationships between religious affiliation, dualism, and free will beliefs.

This work speaks to some potential concerns about motivated reasoning and belief in free will. Manuel Vargas notes that a conspicuously large percentage of academic philosophers who are incompatibilists also self-identify as Christians. The same contingent connections appear to characterize commonsense thinking about free will. That is, self-identifying as a Christian seems to lower the conceptual cost of adopting libertarian commitments, which might encourage Christians to rationalize poor arguments in favor of incompatibilism as convincing. Vargas calls this the Runeberg problem, and marks it out as a distinct form of hindsight bias in service of justifying religious commitments (Vargas, 2016).

The current research provides a more nuanced view of commonsense thinking about free will. There appears to be nothing about Christianity that inclines people toward adopting a substantive metaphysical thesis about free will. We believe that people might rationalize low quality arguments that favor positions supportive of a Christian worldview. However, a particular view on free will does not appear to be one of these positions. Christianity seems flexible with respect to the nature of free will. This appears 
to undercut the claim that Christians are susceptible to motivated reasoning about arguments that support incompatibilism about free will.

\section{References}

Burhmester, M., Kwang, T., and Gosling, S. (2011). Amazon's Mechanical Turk: A new source of inexpensive, yet high-quality data? Perspectives on Psychological Science, 6, 3-5.

De Brigard, F., Mandelbaum, E., and Ripley, D. 2009. Responsibility and the Brain Sciences. Ethical Theory and Moral Practice 12, 511-24.

Deery, O., Davis, T., \& Carey, J. (2014). The free-will intuitions scale and the question of natural compatibilism. Philosophical Psychology, 1-26.

Forstmann, M. and Burgmer, P. 2018. A free will needs a free mind: Belief in substance dualism and reductive physicalism differentially predict belief in free will and determinism. Consciousness and Cognition 63: 280-93.

Greene, J. and Cohen, J.D. 2004. For the law, neuroscience changes nothing and everything. Philosophical Transactions of the Royal Society B 359:1451, 1775-85.

Henrich, J., Heine, S.J., and Norenzayan, A. 2010. The weirdest people in the world? Behavioral and Brain Sciences 33:2-3, 61-83.

Jacobs, J. and O'Connor, T. 2013. Agent Causation in a Neo-Aristotelian Metaphysics. In S.C. Gibb, E.J. Lowe, and R.D. Ingthorsson (Eds.) Mental Causation and Ontology (Oxford: Oxford University Press), 173-92.

Kim, J. 2011. From Naturalism to Physicalism: Supervenience Redux. Proceedings and Addresses of the American Philosophical Association 85:2, 109-34.

Knobe, J. 2014. Free will and the scientific vision. In E. Machery \& E. O'neill (Eds.), Current controversies in experimental philosophy (pp. 69-85). New York: Routledge.

Knobe, J. and Doris, J. 2010. Responsibility. In J. Doris (Ed.) The Moral Psychology Handbook (Oxford: Oxford University Press). 
Lewis, A.R., Djupe, P.A., Mockabee, S.T., and Su-Ya Wu, J. 2015. The (Non) Religion of Mechanical Turk Workers. Journal for the Scientific Study of Religion 54:2, 419-28.

Lowe, E.J. 2013. Substance Causation, Powers, and Human Agency. In S.C. Gibb, E.J. Lowe, and R.D. Ingthorsson (Eds.) Mental Causation and Ontology (Oxford: Oxford University Press), 153-72.

Mele, A. 2014. Free Will and Substance Dualism: The Real Scientific Threat to Free Will? In W. Sinnott-Armstrong (Ed.) Moral Psychology, Vol. 4: Free Will and Responsibility (Cambridge, MA: MIT Press).

Monroe, A. E., \& Malle, B. F. (2010). From uncaused will to conscious choice: The need to study, not speculate about people's folk concept of free will. Review of Philosophy and Psychology, 1, 211-224.

Montague, P.R. 2008. Free Will. Current Biology 18:14, R584.

Murray, D. and Nahmias, E. 2014. Explaining Away Incompatibilist Intuitions. Philosophy and Phenomenological Research 88:2, 434-67.

Nadelhoffer, T., Shepard, J., Nahmias, E., Sripada, C., and Ross, L.T. 2014. The Free Will Inventory: Measuring Beliefs about Agency and Responsibility. Consciousness \& Cognition 25, 27-41. https://doi.org/10.1016/j.concog.2014.01.006.

Nahmias, E. (2011). Intuitions about free will, determinism, and bypassing. In R. Kane (Ed.), The Oxford handbook on free will ( $2^{\text {nd }}$ edition: pp. 555-576). New York: Oxford University Press.

Nahmias, E. (2014). Is free will an illusion? Confronting challenges from the modern mind sciences. In W. Sinnott-Armstrong (Ed.), Moral psychology: Freedom and responsibility (Vol. 4: pp. 1-25). Cambridge, MA: MIT Press.

Nahmias, E., Morris, S., Nadelhoffer, T., \& Turner, J. (2005). Surveying free will: Folk intuitions about free will and moral responsibility. Philosophical Psychology, $18(5), 561-584$.

Nahmias, E., Morris, S., Nadelhoffer, T., \& Turner, J.. (2006). Is incompatibilism intuitive? Philosophy and Phenomenological Research, 73, 28-53.

Nichols, S., \& Knobe, J. (2007). Moral responsibility and determinism: The Cognitive science of folk intuition. Nô̂s, 41, 663-685.

Paolacci, G., Chandler, J., \& Ipeirotis, P. (2010). Running experiments on Amazon Mechanical Turk. Judgment and Decision Making, 5, 411-419. 
Rand, G. (2012). The promise of Mechanical Turk: How online labor markets can help theorists run behavioral experiments. Journal of Theoretical Biology, 299, 172179.

Steward, H. 2012. A Metaphysics for Freedom (Oxford: Oxford University Press).

Timpe, K. and Jacobs, J. 2016. Free Will and Naturalism: How to be a Libertarian, and a Naturalist Too. In K. Clark (Ed.) The Blackwell Companion to Naturalism (London: Wiley), 319-35.

van Inwagen, P. (2004). Freedom to Break the Laws. Midwest Studies in Philosophy 28(1), 334-50. https://doi.org/10.111/j.1475-4975.2004.00099.x

Vargas, M. 2013. Building Better Beings (Oxford: Oxford University Press).

Vargas, M. 2014. Reconsidering Scientific Threats to Free Will. In W. Sinnott-Armstrong (Ed.) Moral Psychology, Vol. 4: Free Will and Moral Responsibility (Cambridge, MA: MIT Press), 217-25.

Vargas, M. 2016. The Runeberg Problem: Theism, Libertarianism, and Motivated Reasoning. In K. Timpe and D. Speak (Eds.) Free Will \& Theism: Connections, Contingencies, and Concerns (Oxford: Oxford University Press), 27-47.

Wisniewski, D., Deutschländer, R., \& Haynes, J-D. (2019). Free will beliefs are better predicted by dualism than determinism beliefs across different cultures. PLoS ONE, 14(9), e0221617. https://doi.org/10.1371/journal.pone.0221617

Wright, J.C., Nadelhoffer, T., Perini, T., Langville, A., Echols, M., and Venezia, K. (2017). The psychological significance of humility. The Journal of Positive Psychology 12(1), 3-12. https://doi.org/10.1080/17439760.2016.1167940. 